\title{
RITUAL MA'ATENU SEBAGAI MEDIA KONSTRUKSI IDENTITAS KOMUNITAS MUSLIM HATUHAHA DI PELAUW MALUKU TENGAH
}

\author{
Yance Z. Rumahuru \\ Program Studi Agama dan Lintas Budaya Sekolah Pascasarjana \\ Universitas Gadjah Mada \\ Email: rumahuru@yahoo.com
}

Irwan Abdullah dan Pujo Semedi

Fakultas Ilmu Budaya Universitas Gadjah Mada

Abd. Khalik Latuconsina

Fakultas Syari'ah IAIN Ambon

\begin{abstract}
This article aims to expalin identity construction of the Hatuhaha muslim community in Pelauw territory, one which use ritual as its main arena. Data on ma'atenu ritual was collected through of ma'atenu implementation, and interviewing of informants in Pelauw.There are ritual partisans and ritual leaders who use symbols in the ritual. The article relates the present ritual to their historical evens and the current condition of local community. This research concludes that (1) the ritual has been a useful and strategic media for identity construction, and (2) through the ritual implementationof ritual, the interpersonal olidarity of Pelauw poeple or Hatuhaha muslim community has been well-developed, it is knoum locally the maningkamu relation.
\end{abstract}

Keywords: Identity, Ritual, Media, Construction, Ma'atenu.

\begin{abstract}
ABSTRAK
Artikel ini bertujuan menjelaskan konstruksi identitas komunitas Muslim Hatuhaha di negeri Pelauw, yang berlangsung dalam ritual sebagai arena utamanya. Mengapa ritual dijadikan sebagai sarana atau media konstruksi identitas merupakan hal yang ingin dijawab dalam tulisan ini. Data tentang ritual ma'atenu diperoleh melalui pengamatan terhadap pelaksanaan ma'atenu dan wawancara dengan sejumlah informan di Pelauw. Hal-hal yang diamati antara lain peserta atau partisan ritual, pemimpin ritual, tempat, dan waktu ritual serta penggunaan simbol-simbol lain dalam ritual tersebut. Cara menganalisa ritual adalah dengan mengaitkan pelaksanaan ritual saat ini dengan peristiwa historis mereka dan dihubungkan juga dengan kondisi kekinian komunitas setempat. Penelitian ini menemukan konsep ritual, yaitu (1) ritual menjadi media yang strategis dan baik bagi konstruksi identitas, (2) melalui pelaksanaan ritual terbangun solidaritas antarsesama warga keturunan Pelauw atau komunitas muslim Hatuhaha dalam istilah setempat disebut dengan ikatan maningkamu.
\end{abstract}

Kata Kunci:Identitas, Ritual, Media, Konstruksi, Ma'atenu. 


\section{PENGANTAR}

Studi ritual komunal penting saat ini untuk melihat cara kelompok-kelompok masyarakat mengkonkritkan hal-hal abstrak terkait pandangan hidup dan kepercayaan mereka, serta cara menghadirkan sejarahnya saat ini dengan dikemas dalam berbagai simbol ritual. Bagaimana satu komunitas mengkonstruksikan identitas kelompoknya dalam ritual merupakan isu yang dibahas dalam artikel ini. Ritual dan identitas memiliki hubungan erat karena melalui ritual, maka kelompok-kelompok pelaksana ritual mengkomunikasikan dan merefleksikan eksistensinya melalui berbagai simbol, yang sarat makna dan sekaligus menjadi penanda identitasnya. Penyebab ritual memiliki posisi penting dalam membicarakan identitas sebagai berikut: Pertama, ritual merupakan media untuk memediasi dua atau lebih entitas yang berbeda, sekaligus penyeimbang dalam kosmos. Kedua, ritual merupakan suatu transformasi sikap dari yang profan kepada sesuatu yang sakral (Abdullah, 2002; Rumahuru, 2009: 283-284).

Artikel ini mengacu pada penelitian lapangan di Pelauw, yaitu satu kampung Islam tua di Maluku Tengah. Pertanyaan yang hendak dijawab di sini mengapa ritual dijadikan sebagai media konstruksi identitas komunitas Muslim Hatuhaha di negeri Pelauw. Secara umum ritual dipandang kebanyakan orang sebagai suatu rutinitas dan menjadi hal biasa, tetapi penelitian ini melihat bahwa ritual berperan memberi informasi tentang hal-hal yang berkaitan dengan kehidupan sosial satu komunitas atau individu tertentu. Dalam hal ini pelaksanaan suatu ritual menghadirkan berbagai elemen, termasuk peristiwa masa lalu yang dikonstruksi dan dimaknai secara baru. Ma'atenu atau disebut juga sebagai cakalele adat dijadikan subjek studi ini adalah ritual komunal masyarakat Hatuhaha di Pulau
Haruku Maluku Tengah, yang dikonstruksi dari konteks perang orang-orang tua Hatuhaha masa lalu untuk menarasikan keperkasaannya di dalam menegakkan eksistensi Islam di Pulau Haruku dan menolak kehadiran bangsa Portugis dan Belanda di wilayah tersebut. Waktu pelaksanaan ritual ma'atenu adalah tiga tahun sekali tahun dan secara rutin dilakukan di negeri Pelauw sebelum Indonesia merdeka hingga kini.

Dalam tulisan ini dimaksudkan dengan identitas, yaitu identitas kelompok atau identitas sosial. Studi tentang identitas Muslim Hatuhaha di negeri Pelauw diletakan dalam perspektif bahwa identitas merupakan sesuatu yang diproduksi, tetapi sekaligus dikonstruksi. Dalam hal ini, identitas adalah proses penamaan atau penempatan dari dalam suatu kategori atau konstruksi sosial tertentu. Identitas dibangun secara sosial mengandung pengertian, seseorang mengekspresikan dirinya yang kemudian mendapat penilaian dan penerimaan oleh kelompok lain. Identitas, dengan sendirinya merupakan sesuatu yang diciptakan dan memiliki dinamika atau ada dalam suatu proses yang dinamis (Barker, 2006; van Meijl, 2004; Salway, 2006; Plumer, 1994). Identitas kelompok dalam perspektif psikologi sosial memiliki konotasi lebih spesifik dengan menunjuk pada devinisi diri dalam pengertian keanggotaan seseorang dalam berbagai kelompok sosial. Konsep identitas dikembangkan berdasarkan hipotesis bahwa individu-individu menilai secara positif perbedaan dimiliki pada diri kelompoknya untuk dibandingkan dengan kelompok lain dalam hal mencapai identitas sosial yang positif. Konsep tentang identitas sosial atau kelompok dapat dipahami dengan melihat hubungan antara individu-individu dari satu kelompok dengan individu-individu dari kelompok lain. Seorang individu memosisikan diri sebagai bagian dari identitas kelompok karena memiliki emosi dan nilai yang sama dengan individu-individu lain dalam kelompok tersebut. 
Mengacu pada pemikiran bahwa kelompok tertentu hanya eksis dalam hubungan dengan kelompok lain, maka identitas sosial dapat dimaknai bila berada dalam hubungan dengan kelompok lain di luar kelompok sendiri (Hewitt, 2003:110-113). Pengertian identitas sosial sebagai berikut:

"social identification has to do with which groups a person belongs to, who her or she identities with, how pople establish and maintain invisible but socially effects boundaries between us and them" (Eriksen, 2004:156-157).

Secara antropologis bahwa konsep identitas sosial mengandung makna yang sama dengan konsep identitas etnis. Istilah etnis mengacu pada masalah perasaan bersama atau senasib dari satu kelompok etnik. Tumbuhnya perasaan ini merupakan produk dari sejarah dan asal usul yang diwarisi. Dalam pengertian yang lebih umum, istilah etnisitas juga merujuk keseluruhan aspek tentang masalah-masalah etnis dan mengacu pada hal-hal yang sifatnya biologis, maupun aspek non- fisik seperti kepercayaan, pengetahuan, budaya, agama, bahasa, dan adat-istiadat yang diwarisinya (Eriksen, 2002: 3-4; Reynolds, 2002).

Konstruksi identitas dalam penulisan ini dikonsepkan sebagai identifikasi diri atau kelompok tertentu dalam satu ruang sosial dalam rangka menghasilkan ekspresi dinamis dari diri atau kelompok tersebut dan mendapat pengaruh secara internal dan eksternal. Dalam hal ini, konstruksi identitas diri maupun kelompok mendapat pengaruh dari kebudayaan dan kondisi sosial sendiri maupun kelompok lain di luar kelompok sendiri. Konstruksi identitas terjadi dalam ruang dan struktur sosial maupun kebudayaan tertentu secara dinamis.

Para ahli sosiologi dan antropologi memahami ritual sebagai berikut: pertama, sarana yang digunakan untuk menghasilkan, mengalami, dan untuk membenarkan keyakinan dan gagasan sebagai hal yang nyata oleh komunitasnya (Durkheim 2001, 1984). Kedua, ritual dilihat sebagai pembenaran kesatuan komunal (Turner 1967, 1977). Melalui pelaksanaan ritual, maka manusia atau orang-orang yang melakukan ritual merasa akrab atau dekat dengan subjek yang kudus dan mendapat perlindungan atau rasa aman (Bell, 1992; Susanto, 1987; Dhavamony, 1995; Gennep 1968). Tindakan ritual dibedakan dalam empat kategori. Pertama, tindakan magi yang dikaitkan dengan penggunaan bahan-bahan yang bekerja karena daya-daya mistik. Kedua, tindakan religius dan kultus para leluhur, ketiga, ritual yang mengungkapkan hubungan sosial dan merujuk pada pengertian-pengertian mistik. Keempat, ritual yang meningkatkan produktivitas atau kekuatan atau pemurnian dan perlindungan (Dhavamony,1995: 175). Di dalam ritus dan tingkah laku yang dikeramatkan, maka seseorang akan menemukan tujuan religiusnya (Geertz, 1992:32).

Konsep ritual tersebut di atas menunjukkan bahwa ritual efektif untuk mengkonkritkan hal-hal yang abstrak agar dapat dipahami. Ritual juga dapat digunakan untuk mensakralkan praktek sehari-hari kelompok-kelompok masyarakat, sekaligus memberi makna baru terhadap praktek tersebut. Dalam perspektif ini penulis melihat bahwa ritual menjadi bagian integral yang penting dari kehidupan komunitas muslim Hatuhaha di Pelauw dan membedakannya dengan komunitas muslim lain di Maluku Tengah, maupun wilayah kepuluan Maluku secara keseluruhan.

Guna menganalisis ritual ma'atenu, penulis mengikuti model yang dipraktekkan oleh Robert Wessing dengan mengkaji tari seblang di Banyuwangi Jawa Timur. Dalam hal ini setiap partisan ritual baik penari, pendamping penari, badut, busana, kelompok musik, sesaji maupun keadaan trans atau kemasukan roh pada penari 
ditafsir dan diberi makna masing-masing, dan memiliki hubungan satu dengan yang lain sehingga hasilnya terintegrasi menjadi satu keutuhan. Model ini digunakan dalam menganalisis máatenu, merupakan ritual khas komunitas Muslim Hatuhaha di negeri Pelauw. Cara menganalisis ritual adalah dengan mengaitkan pelaksanaan ritual saat ini dengan peristiwa historis mereka dan dihubungkan juga dengan kondisi kekinian komunitas setempat.

\section{PEMBAHASAN Persiapan Ritual}

Beberapa bulan sebelum pelaksanaan ma'atenu, pemerintah negeri membentuk tim pelaksana yang terdiri dari keterwakilan semua soa dalam negeri. Melalui kerja sama dengan kepala-kepala soa, rencana pelaksanaan ma'atenu dikomunikasikan baik kepada anakanak soa dan upu ana ${ }^{1}$ yang ada di kampung halaman maupun yang berada di luar kampung (di perantauan), untuk mendaftarkan diri sebagai peserta. Setelah pendaftaran pada soa, kepala soa melanjutkan ke tim pelaksana pada tinggkat negeri (kampung). Seluruh peserta yang diusulkan oleh masing-masing soa dan ditetapkan sebagai peserta atau partisipan ma'atenu pada periode tersebut. Hal ini dapat dipahami dengan melihat penuturan informan di bawah ini:

...untuk ikut ma'atenu, orang-orang diundang dari samua soa par jadi (untuk menjadi) peserta. Jadi katong (kami) tahu barapa peserta dari masing-masing soa atau mata rumah. Biasa kalu su (bila telah) dekat waktu par biking (untuk melaksanakan) ma'atenu, su ada (terdapat) pengumuman dan dari jauh-jauh hari peserta dari masing-masing soa su lapor diri (Taha Tualepe, 58 th, tokoh masyarakat Pelauw).

\footnotetext{
${ }^{1}$ Upu ana (bahasa Hatuhaha) adalah sebutan kepada anak cucu dari leluhur atau marga tertentu. Penyebutan ini terutama ditujukan kepada anak cucu dari orang perempuan marga tertentu. Di Pelauw, upu ana mendapat penghormatan khusus sehingga bila ada acara pada marga atau soa, mereka diundang dan para upu ana diberi perhatian khusus.
}

Orang yang hendak mengikuti ritual ma'atenu perlu mempersiapkan diri (jasmani maupun rohani) secara baik karena ritual ini membutuhkan kekuatan fisik dan kondisi kejiwaan yang stabil. Fisik dan kejiwaan yang baik diperlukan oleh setiap calon peserta karena dalam ritual ini, peserta mengatraksikan atau mendemonstrasikan kondisi perang dengan membawah perlengkapan perang tradisional berupa parang atau kalewang, layaknya seorang prajurit tentara yang masuk medan pertempuran lengkap dengan senjatanya. Para peserta akan menempuh perjalanan sekitar 10 KM pergi-pulang (PP) dan berlari atau berjalan cepat melewati jalan berbatuan, menyeberang sungai, dan ada juga yang ke gunung. Selama perjalanan sampai dengan puncak ritual para peserta menguji kekebalan diri dengan memotong, mengiris dan menikam perut, dada, tangan, kaki, leher, pipi, lidah, dan kepala dengan alat tajam yang di bawahnya

Peserta ma'atenu umumnya adalah lakilaki dewasa (pemuda dan orang tua), tetapi belakangan ini ada anak-anak juga yang ikut. Mengingat konteks pelaksanaan ma'atenu adalah perlawanan atau perang, maka peserta ma'atenu disimbolkan sebagai prajurit Hatuhaha. Untuk itu, syarat yang patut dipenuhi oleh mereka yang hendak mengikuti ma'atenu, yaitu pertama, mendapatkan restu atau persetujuan keluarga. Restu orang tua dan anggota keluarga dianggap sebagai keikhlasan mereka mengikutsertakan anak dan saudara mereka terlibat dalam medan pertempuran dan mereka siap atau rela menerima segala konsekwensi yang terjadi atas diri anak dan keluarganya itu. Begitu pula yang sudah menikah, perlu mendapat izin dan restu sang istri. Kedua, mencukur rambut. Mencukur rambut merupakan akta simbolis sebagai bagian dari proses pembersihan diri dan sekaligus menyatakan kesiapan selaku prajurit yang siap masuk medan perang.

\section{Pelaksanaan Ritual}

Malam hari sebelum besok dilaksanakan 
ritual, umumnya peserta sudah berkumpul pada rumah soa kecil masing-masing. Dalam hal ini salah satu rumah dari anggota marga yang dituakan. Rumah soa kecil dibedakan dengan rumah soa besar atau disebut juga dengan rumah tua, yang menjadi pusat kegiatan di soa tersebut. Rumah soa besar ditempati oleh seorang tua dari garis keturunan ayah yang tertua atau dituakan dari marga dan soa tersebut. Rumah soa kecil merupakan bagian dari warga di rumah soa besar yakni rumah salah satu anggota marga atau soa yang dituakan dalam marga, dan masih memiliki hubungan yang sangat dekat, seperti bapak ibu atau kakek nenek mereka merupakan adik kakak kandung. Maksud berkumpul di sini adalah agar bersama-sama dengan anggota marga atau soa yang lain keesokan harinya secara bersama keluar menuju rumah tua atau rumah soa besar dari soa yang bersangkutan. Penulis melihat bahwa saat anak-anak soa dari satu keluarga dekat berkumpul pada rumah soa kecil, kesempatan ini digunakan oleh orang yang tua pada mata rumah tersebut untuk menjelaskan hal-hal yang perlu diperhatikan dalam mengikuti ma'atenu. Seorang informan yang merupakan peserta ma'atenu 2009 bertutur sebagai berikut:

...waktu datang di rumah soa kecil katong (kita) diperkenalkan oleh orang tua-tua tentang katong pung kapitan atau pemimpin perang asal soa, dan dong (mereka) cerita tentang kapitang itu par katong. Waktu orang tua-tua carita bagitu (tentang keperkasaan kapitan) ada di antara katong peserta yang su ka'a (bahasa Pelauw) artinya kemasukan (M. Latuconsina, 25 tahun).

Semua peserta yang tidur di rumah soa kecil pagi-pagi benar sudah bangun dan sarapan, mandi, mengenakan pakaian putih, dan bersiap-siap untuk ke rumah tua. Ada juga sebagian peserta yang tidur di rumahnya sendiri, tetapi jam $06.00 \mathrm{~s} / \mathrm{d} 06.30$ mereka sudah bergabung di rumah soa kecil. Pukul $07.00 \mathrm{~s} / \mathrm{d}$ 08.00, seluruh peserta sudah berada di rumah tua masing-masing karena ritual akan dimulai dari sini.

Seluruh rangkaian ma'atenu dipimpin oleh seorang Ma'ahala Lahat dan dibantu oleh beberapa orang Ma'ataru Ame, semuanya berasal dari marga atau soa Tualepe. Ma'ahala Lahat adalah orang yang membawakan doadoa dan memimpin seluruh ritual ma'atenu. Sedangkan Ma'ataru Ame adalah mereka yang menjaga keteraturan dan ketertiban para peserta atau untuk menenangkan mereka selama proses ritual dilakukannya. Selain menenangkan para peserta, Ma'ataru Ame juga dapat memancing para peserta yang belum $k a^{\prime} a^{2}$ untuk $k a^{\prime} a$ dan memukul badan mereka dengan parang atau benda lain yang ada di tangan mereka, atau membentak mereka dengan suara keras. Sebagai pemimpin ritual, $M a^{\prime}$ ahala Lahat merupakan orang yang bertanggung jawab sepenuhnya terhadap keselamatan peserta máatenu. Selama pelaksanaan ritual, Ma'ahala Lahat menggendong satu kain warna merah yang disebut "kain lahat". Menurut seorang informan, kain itu tidak boleh lepas dari tangannya karena di situ terletak "keselamatan" seluruh peserta. Saya memahami bahwa Ma'ahala Lahat adalah simbol dari kuasa tertinggi ${ }^{3}$ dan $M a^{\prime}$ ataru Ame merupakan wakil-wakil Ma'ahala Lahat yang menjadi simbol dari kehadiran leluhur.

\footnotetext{
${ }^{2} \mathrm{Ka}^{\prime}$ a adalah peristiwa masuknya roh leluhur atau kapitan dalam diri peserta ma'atenu.

${ }^{3}$ Di Pelauw maupun Maluku Tengah secara keseluruhan tidak dikenal konsep dewa-dewi seperti pada masyarakat di Jawa dan Bali atau tempat lain, tetapi di kenal adanya kuasa tertinggi atau paling besar, yang disebut dalam bahasa lokal masing-masing. Suku Wemale yang merupakan suku besar di Maluku Tengah misalnya menyebut kuasa itu dengan nama Upu Lainte Takule artinya Tuhan Langit dan Bumi. Orang Hatuhaha yang telah mendapat pengaruh Islam menyebut kuasa tertinggi itu dengan nama "Allah Taalah" artinya Allah yang berkuasa. Dalam praktek hidup sehari-hari, leluhur dianggap sebagai wakil Allah. Pemahaman bahwa leluhur yang telah meninggal menjadi perantara antara kuasa tertinggi tersebut dengan manusia yang hidup atau anak-cucucicit saat ini tampak dalam pelaksanaan ritual-ritual di Pelauw.
} 
Kain lahat dapat dilihat sebagai simbol dari jiwa peserta ma'atenu. Apabila mengikuti ma'atenu mengalami kemasukan roh leluhur dan tidak menyadari apa yang dilakukannya, maka kain lahat perlu dijaga. Peserta ma'atenu dianalogikan sebagai anak dan disimbolkan oleh kain lahat yang digendong dan dijaga ketat oleh Ma'ahala Lahat selaku ibu yang menggendong anaknya. Keselamatan anak sangat ditentukan oleh sang ibu. Energi yang dimiliki Ma'ahala Lahat kemudian dibagikan kepada seluruh peserta sehingga semuanya memiliki kekuatan sama dalam mengikuti ritual.

Busana yang dikenakan oleh peserta ma'atenu semuanya sama, terdiri dari: Baju kurung putih, celana tali (berbentuk celana koko) putih, ikat pinggang merah, ikat kepala putih. Warna merah dan putih menjadi warna utama masyarakat Hatuhaha, digunakan sejak orang tua-tua dahulu. Hal ini tampak dalam pernyataan seorang informan sebagai berikut:

Warna merah dan putih yang digunakan di sini tidak ada hubungan dengan warna bendera Indonesia Merah Putih karena sebelum ada Indonesia katong pung orang tua-tua su pake warna merah putih (KH. Latukonsina, 47 tahun, tokoh masyarakat Pelauw).

Warna merah menunjuk pada keteguhan dan keberanian orang Hatuhaha mempertahankan dan memperjuangkan identitasnya. Adapun warna putih menunjuk pada ketulusan dan keterbukaan orang Hatuhaha. Setelah mendapat pengaruh Islam, warna putih juga melambangkan keadaan yang bersih atau kesucian dari kemunitas Hatuhaha. Sejak orang tua-tua dulu hingga kini, warna putih dominan digunakan oleh tokoh agama, sedangkan kombinasi putih dan merah digunakan oleh para pemimpin kelompok yang dikenal dengan kapitan atau penglima perang. Cara berpakaian peserta ma'atenu sekarang sudah diseragamkan. Menurut seorang informan, ikat pinggang warna merah yang dikenakan oleh peserta tidaklah tepat, yang benar adalah seluruh peserta mengenakan ikat pinggang warna putih. Hal ini tampak dari pernyataan informan berikut ini:

...dulu seng (tidak) seperti ini. Mestinya ikat pinggang peserta ma'atenu adalah warna putih. Orang yang menggunakan ikat pinggang warna merah cuma (hanya) pemimpin atau kapitan, mar (tetapi) saat ini su sabarang (tidak benar lagi), semua peserta menggunakan ikat pinggang warna merah (Taha Tualepe, 58 th, tokoh masyarakat Pelauw).

Penggunaan warna di kalangan masyarakat Hatuhaha di Pelauw seperti disebut di atas telah menunjuk pada struktur dan fungsi dalam masyarakat. Warna merah hanya digunakan oleh pemimpin perang atau panglima, yang disebut dengan kapitan. Dalam konteks pelaksanaan ma'atenu bahwa yang berhak menggunakan ikat pinggang atau simbol lain warna merah adalah $M a^{\prime}$ ahala Lahat dan Ma'ataru Ame.

Ritual ma'atenu lahir dari konteks perang karenanya peralatan yang digunakan adalah parang atau pedang. Seorang informan menuturkan bahwa duhulu pada masa orang tua-tua mereka, peralatan yang digunakan adalah tombak dan parang, tetapi sekarang hanya parang yang digunakan. Tombak dan parang merupakan peralatan yang digunakan oleh masyarakat di Maluku, bahkan masyarakat Indonesia umumnya sebagai alat perang melawan kolonialisme dan imperialisme hingga memperoleh kemerdekaan 1945. Pengamatan terhadap pelaksanaan ma'atenu tahun 2009 menunjukan bahwa peserta ritual ma'atenu saat ini ada juga yang menggunakan pisau, silet, dan kapak untuk mengiris dan memotong badannya atau anggota tubuh lain dalam rangka menguji kekebalan tubuh mereka.

Tempat pelaksanaan ma'atenu dapat dilihat sesuai dengan pentahapan ritual itu sendiri, dimulai dari rumah tua, ke keramat dan berakhir (puncak acaranya) di halaman masjid dan baileo atau rumah adat. Bila melihat prosesi ritual dari tahap pertama 
ke tahap yang lainnya, dapat disebutkan bahwa tempat pelaksanaan ma'atenu adalah wilayah adat negeri Pelauw. Umumnya orang menyebutkan halaman masjid dan baileo sebagai tempat pelaksanaan ma'atenu. Hal ini karena puncak acara ma'atenu mengambil tempat di halaman masjid dan baileo Pelauw yaitu tempat yang menyatukan dari arah Selatan ke Utara.

Peserta máatenu dibagi menjadi tiga kelompok sesuai arah mata angin dan keramat dari leluhur orang Pelauw. Kelompok pertama ke arah Barat. Kelompok ini dikenal dengan nama Latu Rima. Lokasi keramat mereka adalah Matasiri. Kelompok kedua ke arah Timur. Kelompok ini dikenal dengan nama Tuni Mahua Waelapia, mengikuti nama keramat mereka yang terletak di satu dusun dekat muara sungai Waelapia. Kelompok ketiga adalah ke arah Selatan

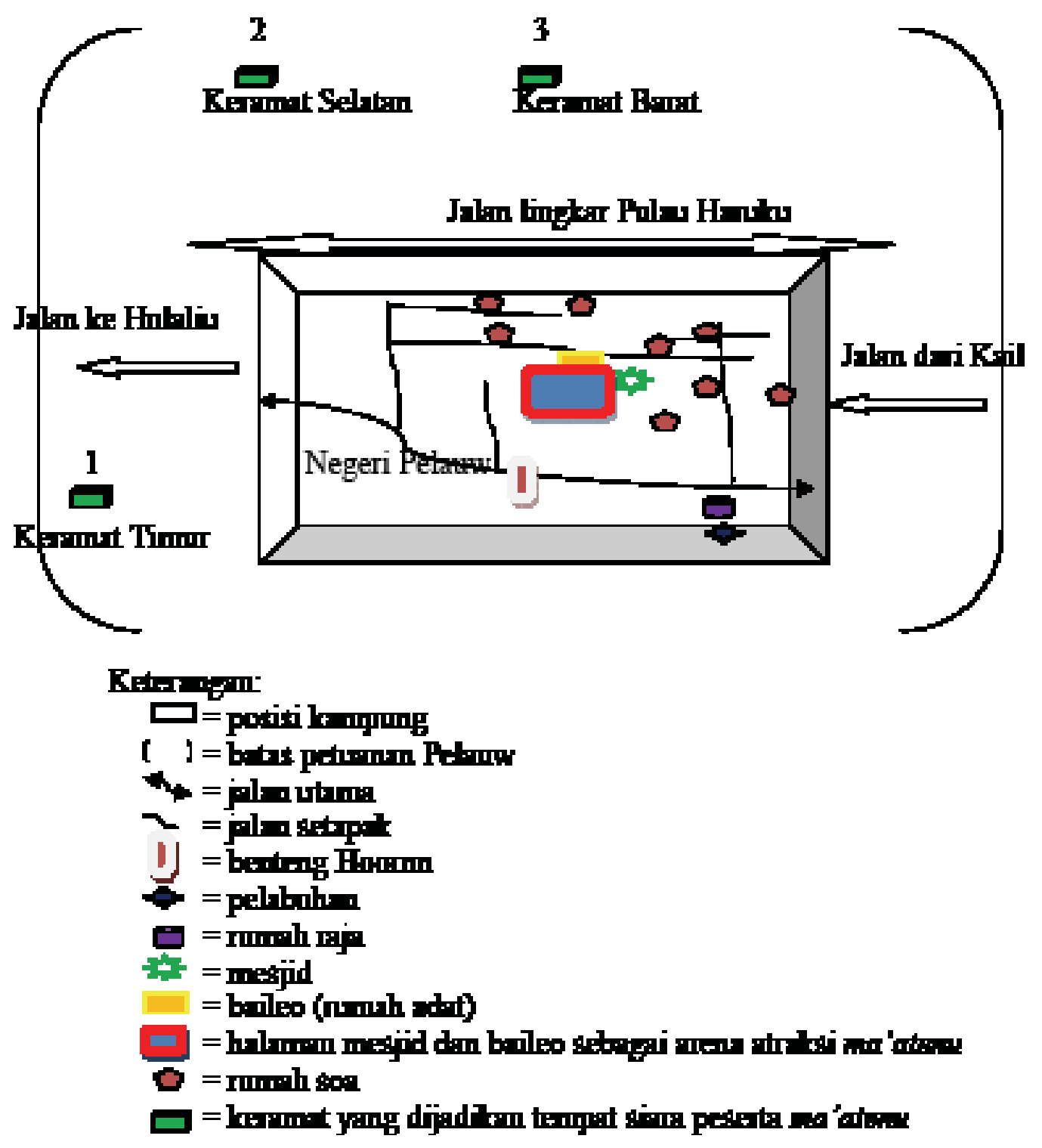

Gambar 1

Posisi negeri Pelauw dan arena pelaksanaan ma'atenu 
(gunung). Kelompok ini dikenal dengan nama Urato Roho Rhima. Sering disebut juga dengan nama Waelurui karena keramat ini terletak di kepala (hulu) sungai Wae Marikee. Nama keramat mereka adalah Te'put. Posisi keramat yang menjadi tempat ziarah peserta maupun halaman masjid dan baileo yang menjadi arena pertunjukan ma'atenu dapat diilustrasikan melalui diagram gambar 1 .

Kelompok atau sektor Barat terdiri dari marga: Latuconsina, Latupono, Latuamury, Sahubawa, dan Talaohu. Kelompok ini tidak berkumpul sekaligus pada satu tempat, tetapi pada dua tempat yang berbeda kemudian bergabung pada satu tempat sebelum ke keramat. Marga Latuconsina, Latupono, dan Latuamury berkumpul di rumah Ela atau rumah nai Latuconsina sedangkan marga Sahubawa dan Talaohu berkumpul di rumah nai Lesirohi, milik soa Sahubawa. Marga atau soa Latuconsina, Latupono, dan Latuamury kemudian bergabung dengan Sahubawa dan Talaohu di rumah nai Lesirohi. Kelompok atau sektor Timur terdiri dari marga: Tualeka, Tuni, Tuahena, dan Tuasikal. Seluruh peserta kelompok ini berkumpul pada rumah adat marga Tualeka. Kelompok Timur dan Barat mengambil Ma'ahala Lahat dan Ma'ataru Ame dari soa Tualepe untuk memimpin mereka. Kelompok atau sektor Selatan terdiri dari marga: Tualepe, Tuankota, Tuakia, Salampessy, dan Angkotasan. Peserta dari kelompok ini semuanya langsung berkumpul pada rumah tua soa Tualepe. Di sini sudah ada Ma'ahala Lahat dan Ma'ataru Ame.

Prosesi ritual berlangsung dari pagi hari hingga sore hari, mulai sekitar jam 07.00 s/d 16.00 waktu setempat. Setiap peserta dipersiapkan di rumah soanya sejak malam hari dan sekitar jam 09.00 mereka sudah keluar dari rumah soa, setelah dibacakan doa dan salawat nabi. Sekitar jam 10.00, semua peserta berjalan menuju keramat masing-masing. Sekitar dua jam peserta berada di keramat. Di keramat mereka membersihkan lokasi keramat dan melakukan doa selamatan, dipimpin oleh $M a^{\prime}$ ahala Lahat, yang diawali dengan membakar damar di keramat. Walau tidak ada sesaji seperti pada sejumlah ritual yang dijumpai di Jawa dan Bali, tetapi pembakaran damar dapat dimengerti sebagai bentuk pemujaan kepada kuasa paling besar atau kuasa tertinggi dan penghormatan kepada leluhur yang telah menjaga dan melindungi mereka. Setelah doa selamatan, peserta menyantap makanan yang telah disediakan oleh sejumlah ibuibu. Sehabis makan bersama di keramat, para peserta menuju kali yang dekat dengan keramat untuk mandi dan selanjutnya kembali ke kampung. Peserta ma'atenu mandi di kali setelah mereka kembali dari keramat dan dalam menuju kampung, ini dapat dipahami sebagai proses pembersihan diri dan kesiapan mengemban tugas sebagai "prajurit Hatuhaha". Orang-orang yang telah mengikuti ma'atenu mengalami perubahan, yakni memiliki keberanian tersendiri dalam hidupnya. Salah satu yang tampak menonjol di Pelauw adalah mereka memiliki keberanian untuk membangun hidup di manapun dan siap terhadap berbagai tantangan. Hal menjadi modal bagi mereka untuk berkompetisi dan berkembang seperti tampak sekarang.

Dalam perjalan kembali ke kampung dan masuk arena atraksi di halaman masjid dan baileo, semua peserta mengalami kemasukan roh kapitan atau leluhur atau $k a^{\prime} a$, dan tampak memiliki kekebalan terhadap benda-benda tajam. Setiap anggota keluarga yang mengantar anak atau saudara atau suami mereka mengikuti ma'atenu memiliki kebanggaan tersendiri saat melihat mereka $k a^{\prime} a$, yang berarti bahwa mereka berhasil mendapat perhatian dari para leluhur atau kapitan. Relasi dengan leluhur begitu penting karena leluhur dianggap dapat memediasi mereka dengan kuasa yang paling besar atau dapat disebut Sang Pencipta. Apabila para pengantar melihat anggota keluarga mereka yang menjadi peserta ma'atenu belum $k a^{\prime} a$, segera dipancing dengan cara bersuara keras 
atau menari-nari mencari perhatian mereka. Beberapa informan yang terlibat dalam ritual ma'atenu menuturkan bahwa bila mereka berjumpa dengan anggota keluarganya, secara serentak mereka mengalami kemasukan roh atau $k a^{\prime} a$. Apalagi kalau mereka melihat ibu atau saudara-saudara perempuan atau istrinya berada di dekat mereka.

Pelaksanaan ma'atenu diramaikan oleh satu grup musik terdiri dari beberapa orang laki-laki dan perempuan, mereka memainkan tifa, dan rebana sambil menyanyikan syairsyair atau lani (bahasa Pelauw) untuk memberikan semangat kepada para peserta ritual. Ada dua lani (syair) yang dinyanyikan berulang-ulang.

Lani 01.

Lani 02.

Tita heu-heu e Tita heu-heu e Upu tua poe yasela

Tura lani rua

Isi ana hutu telu

Mantura lanai irua

Bonbonua ma'atita urat ${ }^{4}$

Lani-lani ini merupakan pujian terhadap leluhur Hatuhaha, dan pada waktu dinyanyikan para peserta ma'atenu pun tampak semakin bersemangat, histeris, dan setiap peserta mendapat kemasukan roh leluhur mereka atau $k a^{\prime} a$. Lani-lani di atas memiliki makna mengingatkan para peserta ma'atenu kepada kegagahan leluhur mereka mempertahankan identitas agama, menyiarkan agama Islam, dan bertempur melawan musuh-musuh mereka. Kelompok musik yang menabuh tifa dan rebana serta menyanyikan lagu atau lania di atas berperan memberi dukungan mental dan semangat perjuangan kepada para peserta ma'atenu.

Ritual ma'atenu sudah harus berakhir sebelum tifa kamis (jam 16.00 WIT), untuk itu sekalipun menempuh perjalanan panjang (sekitar $10 \mathrm{~s} / \mathrm{d} 15 \mathrm{KM} \mathrm{PP)} \mathrm{dan} \mathrm{melelahkan}$ tetapi sesuai waktu yang ditentukan, semua

\footnotetext{
${ }^{4}$ Lani-lani ini sesungguhnya merupakan pujian kepada pasukan perang Hatuhaha, yang disimbolkan dengan memberi semangat kepada Upu Rihia (Kepala Kapitan Hatuhaha) dan Upu Matawoku (Wakil Kapitan Hatuhaha).
}

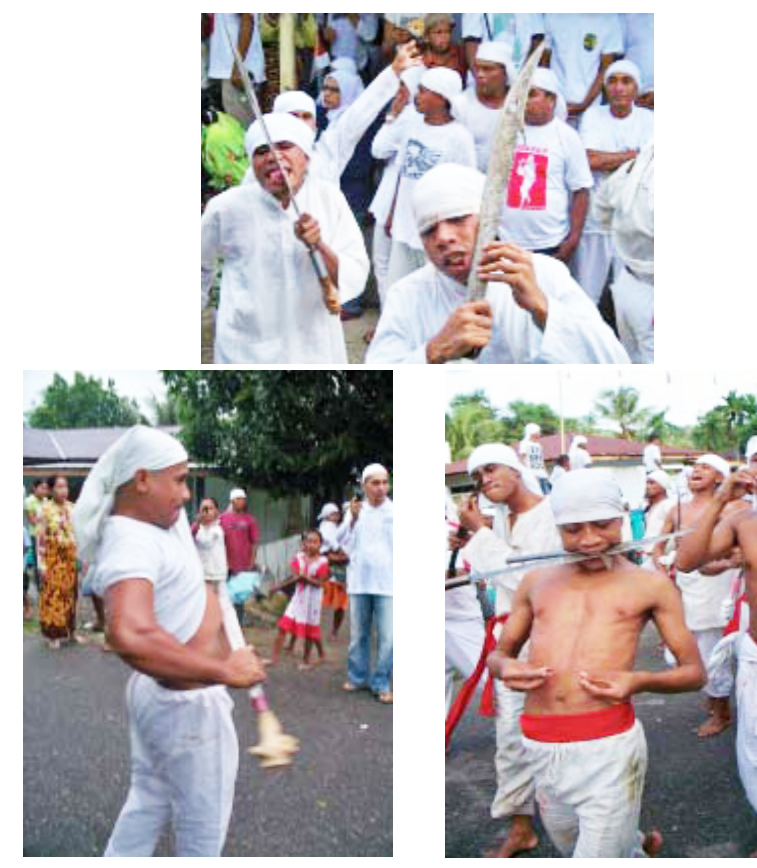

Gambar 02.

Atraksi peserta ma'atenu memotong, menikam dan mengiris badan mereka

(Foto: Y.Z.Rumahuru, Mei 2009)

pasukan sudah berada di halaman masjid dan baileo untuk mempertunjukan kekebalan masing-masing terhadap benda-benda tajam. Atraksi memotong, mengiris, menikam badan, dan anggota tubuh dengan parang, pisau dan benda-benda tajam lain berlangsung di halaman masjid dan baileo sekitar 1 jam s/d 1,5 jam.

Di akhir acara ma'atenu, semua peserta secara teratur satu demi satu masuk ke baileo dan diterima oleh ibu-ibu yang mengalungkan kain ke leher setiap peserta. Pengalungan kain oleh ibu-ibu atau orang perempuan kepada peserta ma'atenu sekaligus menandai berakhirnya ritual ini adalah suatu akta simbolik. Peran seorang ibu atau seorang istri (orang perempuan) sudah tampak sejak persiapan peserta. Sebagaimana disebut sebelumnya bahwa semua laki-laki yang mengikuti ma'atenu tentu mendapat restu dari ibu atau istri mereka. Sama seperti mengikuti ma'atenu membutuhkan restu ibu atau istri, maka mengakhiri ritual ini sejumlah ibu-ibu yang hadir di baileo merupakan representasi 
semua orang perempuan di Pelauw yang menerima kedatangan "prajurit Hatuhaha" dengan ungkapan syukur, karena mereka telah menunaikan tugasnya dengan baik dan dilindungi oleh Allah Taalah.

Seorang informan menjelaskan bahwa pengalungan kain oleh ibu-ibu adalah untuk memulihkan kondisi para peserta dari kemasukan roh leluhur menjadi normal kembali. Hal ini mengandung pengertian bahwa perempuan menjadi sumber harmoni. Fenomena ini menunjukkan bahwa perempuan menjadi sumber energi yang ampuh bagi laki-laki Hatuhaha, yang berarti juga bahwa pengabaian terhadap perempuan berdampak pada konflik atau kehancuran. Peran perempuan di Pelauw tidak hanya tampak pada pelaksanaan ritual seperti ini, tetapi juga dalam kehidupan sehari-hari. Telah disebut sebelumnya bahwa sekalipun masyarakat Hatuhaha manganut sistem patriakal, tetapi perempuan diberi posisi tersendiri dalam hidup bermasyarakat. Realitas perempuan Pelauw dalam ritual sebagai sumber harmoni dan energi bagi laki-laki seperti disebut di atas memberi gambaran bahwa perempuan di manapun patut dihormati, dikasihi dan diberi posisi seimbang dengan laki-laki karena kesuksesan seorang laki-laki turut ditentukan oleh perempuan.

\section{Makna Ritual Ma'atenu}

Pelaksanaan ritual ma'atenu menjadibagian penting dalam kehidupan komunitas muslim Hatuhaha di Pelauw karena ritual dijadikan sebagai momen untuk masing-masing orang mengerjakan dan mengumpulkan amalnya selaku bekal di akhirat nanti. Konsepsi ini begitu kuat sehingga dalam setiap pelaksanaan ritual musiman di negeri Pelauw, anakanak negeri di perantauan berusaha sedapatdapatnya kembali ke negeri untuk mengikuti ritual-ritual yang dilaksanakan. Apabila mereka tidak kembali ke negeri karena alasan yang mendasar seperti pekerjaan yang tidak dapat ditinggalkan, atau waktu yang singkat dan biaya yang terlampau besar padahal mereka memiliki prioritas kebutuhan lain, maka mereka tetap memiliki konstribusi dengan memberi bagian yang menjadi tanggungan mereka untuk mendukung suksesnya pelaksanaan ritual tersebut.

Telah disebut sebelumnya bahwa konteks historis kehadiran ma'atenu adalah perang melawan kolonialisme dan imperialisme yang mengikutsertakan misi kristenisasi oleh orang-orang Portugis dan Belanda, maka pelaksanaan ma'atenu di negeri Pelauw dimaksudkan untuk menegaskan identitas agama (Islam) di Pulau Haruku. Melalui pelaksanaan máatenu saat ini, orang Hatuhaha di Pelauw menarasikan keperkasaan dan heroisme orang Hatuhaha dahulu, dan nilai-nilainya itu diwariskan kepada generasi Hatuhaha turun-temurun. Fenomena pembagian tugas yang baik antara pemimpin ritual atau ma'ahalalahat dengan staf atau ma'ateruamae menunjukan adanya fungsi struktur masyarakat secara baik bahwa kekuasaan tidak dimaknai miliki seseorang atau kelompok tertentu semata, tetapi perlu di bagi. Hal ini berbeda dengan kecenderungan kekuasaan di era ini yang seakan dipusatkan dan dijadikan milik kelompok tertentu saja.

Mengingat ritual máatenu ini dikonstruksi dalam kelompok-kelompok masyarakat yang telah memeluk agama Islam, maka makna ritual ma'atenu dapat dipahami dengan melihat hubungan antara agama (Islam) dan adat yang membentuk manusia Hatuhaha, secara khusus di negeri Pelauw. Memperhatikan konteks kemunculan ritual ma'atenu dan pelaksanaannya saat ini dengan simbol-simbol yang dimiliki, maka beberapa makna ritual ini dapat disebut sebagai berikut: Pertama, makna religius, yakni ketaatan dan penyembahan kepada kuasa tertinggi (Allah Taalah), yang berarti pula menjaga eksistensi agama yang telah dianut. Kedua, makna adatis, yaitu penghormatan kepada leluhur, sekaligus menjaga relasi baik dengan leluhur. Implementasi dari penghormatan kepada 
leluhur adalah melaksanakan tuntutan adat secara baik. Ketiga, makna sosial, yakni membangun solidaritas kelompok atau yang dikenal dengan istilah lokal setempat ikatan maningkamu, yakni ikatan hubungan persaudaraan. Solidaritas kelompok tampak melalui saling tolong-menolong, saling menghormati, dan kerjasama. Makna ritual dan nilai-nilai yang disebut ini merupakan kekuatanyang menjadi modal sosial bagisemua orang Hatuhaha saat ini untuk membangun hidup dan mengalami perubahan.

\section{SIMPULAN}

Deskripsi tentang ritual ma'atenu di negeri Pelauw yang dianalisis ini menunjukan bahwa: pertama, ritual menjadi media yang strategis dan baik bagi konstruksi identitas. Di sini tampak bahwa pelaksanaan ma'atenu secara rutin di Pelauw efektif menjadi sarana sosialisasi nilai yang oleh penulis disebut sebagai media konstruksi identitas. Bahkan, ritual menjadi sarana efektif untuk mereproduksi dan melestarikan identitas orang Muslim Hatuhaha umumnya, secara khusus di negeri Pelauw. Kedua, melalui pelaksanaan ritual terbangun solidaritas antarsesama warga keturunan Pelauw atau komunitas Muslim Hatuhaha dan dalam istilah setempat disebut dengan ikatan maningkamu. Maningkamu atau ikatan persaudaraan menjadi faktor utama orang Peluaw untuk berpartisipasi dalam pelaksanaan ritual.Selain itu, kuatnya gagasan tentang amalan yang diwujudkan malalui ritual, mendorong setiap anak negeri di Pelauw tidak absen dari pelaksanaan setiap ritual, baik melalui kehadiran secara langsung, maupun partisipasi dengan cara yang lain.

\section{DAFTAR PUSTAKA}

Abdullah, I., 2002, Simbol, Makna dan Pandangan Hidup Jawa: Analisis Gunungan pada Upacara Garebek, Yogyakarta: Balai Kajian Sejarah dan Nilai Tradisional. 2007, Konstruksi dan Reproduksi Kebudayaan, Yogyakarta: Pustaka Pelajar.
Bell, C., 1992, Ritual Theory, Ritual Practice, New York: Oxford University Press.

Chauvel, R., 2008, Nationalis, Soldiers And Separatists: The Ambonese islands from colonialism to revolt 1880-1950, (Second impression), Leiden: KITLV Press.

Cortini, M., Mininni, G., and Manuti A., 2004, "The Diatextual Construction of the Self in Short Message Systems". IDENTITY: AN INTERNATIONAL JOURNAL OF THEORY AND RESEARCH, 4(4), 355-370. Copyright (C) 2004, Lawrence Erlbaum sociates, Inc.

Davies, Ch. A., 1999, Reflexive Ethnography: A Guide to Selves and Others, London and New York: Routledge.

Dhavamony, M., 1995, Fenomenologi Agama, Yogyakarta: Kanisius.

Durkheim, E., 2001, The Elementary Forms Of Religious Life, Oxford World's Classics. 1984, The Division of Labor in Society, New York: The Free Press.

Eriksen Th. H., 2002, Ethnicity and Nationalism (second edition), London: Pluto Press , 2002, What is Anthropology?, London: Pluto Press.

Finley, S.A. 2010, "An identity-based understanding of intergroup conflict", Contemporary Justice Review Vol. 13, No. 4, December 2010, hlm: 425-441.

Geertz, C., 1960, The religion Of Java, The University of Chicago Press, Chicago and London.

Hall, Stuart,1991, Old and New Identities, Old and New Ethnicities, dalam Anthony, D.King (editor) Culture Globalization and the WorldSystem: Contemporary Conditions for the Representation of Identity, Hampshire and London: The Macmillan Press.

Hastings-Black, M., 2009, American-Muslim Identity: Advertising, Mass Media + New Media, in Pink Johanna (ed.), Muslim Societies in the Age of Mass Consumption: Politics, Culture and Identity between the Local and the Global, Cambridge Scholars Publishing. 
Herzfeld, M., 1990, “Icon and Identity: Religious Orthodoxy and Social Practice in Rural Crete". Anthropological Quarterly, 63:3 (1990:July) p.109-121, Copyright 2001 Bell and Howell Information and Learning Company, Catholic University of America Press.

Hewitt, J. P., 2003, Self and Society, A Symbolic Interactionist Social Psychology, Boston: A\&B Press.

Jimenes, T.R., 2010, “Affiliative ethnic identity: a more elastic link between ethnic ancestry and culture", Ethnic and Racial Studies, Vol. 33 No. 10 November 2010 pp. 1756-1775.

Mol, H., 1979, "The Identity Model of Religion: How It Compares with Nine Other Theories of Religion and How It Might Apply to Japan" Japanese Journal of Religious Studies, 6:1/2 (1979:Mar./June) p.11-38. Copyright 2006 ProQuest Information and Learning Company, Nanzan Institute for Religion and Culture.

Naroll, R., 1964, "Ethnic Unit Classification". Current Anthropology, hlm: 5-14

Norman, K. D., dan Yvonna, S. L., 1994, Handbook of Qualitative, Sage Publication, International Educational and Professional Publisher, New Delhi.

Pink, J.(ed.), 2009, Muslim Societies in The Age of Mass Consumption: Politics, Culture and Identity The Local and The Global, UK: Cambridge Scholars Publishing.

Plumer, K., 1999, “Identity”, dalam Willyam Outhwhite dan Tom Bottemore (eds.), The Blackwell Dictionary of Twentieth Century Sosial Through, Oxford: Blackwell Publishers.
Rumahuru, Y.Z., 2009, Wacana Kekuasaan Dalam Ritual: Studi Kasus Ritual Ma'atenu di Pelauw, dalam Irwan Abdullah (ed.), Dinamika Masyarakat dan Kebudayaan Kontemporer, Yogyakarta: Pustaka Pelajar dan TICI Publication. 2010, "Dinamika Identitas Komunitas Muslim Hatuhaha di Pulau Haruku Maluku Tengah", Jurnal Masyarakat Indonesia, Edisi XXXVI, No.1, hal. 93-112.

Schilbrack, K., ed. 2004, Thingking Throug Rituals: Philosophical Perspective, New York: Routledge.

Turner, V.,1967, The Forest Of Symbols: Aspects of Ndembu Ritual, London: Cornell University Press.

1977, The Ritual Process: Structure and Anti-Stucture, London: Cornell University Press.

Von Benda-Beckmann, F. dan von BendaBeckmann, K., 2011, Identitas dalam Perselisihan di Minangkabau, dalam Ramstedt, M. dan Thufail, F.I. (eds.), Kegalauan Identitas: Agama, Etnisitas dan Kewarganegaraan Pada Masa Pasca-Orde Baru, Jakarta: Gramendia Widiasarana.

Wessing, R., 1999, “A Dance of Life: The Sablang of Banyuwangi, Indonesia, Bijdragen Tot De Taal-, Land-En Volkendkunde, Deel 155, pages 644-682.

Wimberley, D.W. 1989, "Religion and Role-Identity: A Structural Symbolic Interactionist Conceptualization of Religiosity", The Sociological Quarterly, Volume 30, No.1, pages 125-142. Copyright 2005 ProQuest Information and Learning Company, University of California Press. 